archives-ouvertes

\title{
Controls on the seafloor exposure of detachment fault surfaces
}

\author{
Jean-Arthur Olive, Ross Parnell-Turner, Javier Escartin, Deborah Smith, \\ Sven Petersen
}

\section{To cite this version:}

Jean-Arthur Olive, Ross Parnell-Turner, Javier Escartin, Deborah Smith, Sven Petersen. Controls on the seafloor exposure of detachment fault surfaces. Earth and Planetary Science Letters, Elsevier, 2019, 506, pp.381-387. 10.1016/j.epsl.2018.11.001 . hal-02324084

\section{HAL Id: hal-02324084 \\ https://hal.archives-ouvertes.fr/hal-02324084}

Submitted on 21 Oct 2019

HAL is a multi-disciplinary open access archive for the deposit and dissemination of scientific research documents, whether they are published or not. The documents may come from teaching and research institutions in France or abroad, or from public or private research centers.
L'archive ouverte pluridisciplinaire HAL, est destinée au dépôt et à la diffusion de documents scientifiques de niveau recherche, publiés ou non, émanant des établissements d'enseignement et de recherche français ou étrangers, des laboratoires publics ou privés. 


\section{Controls on the seafloor exposure of detachment fault surfaces}

4 Jean-Arthur Olive ${ }^{1 *}$, Ross Parnell-Turner ${ }^{2,3}$, Javier Escartín ${ }^{4}$, Deborah K. Smith ${ }^{5}$, and 5 Sven Petersen 6

$7 \quad{ }^{1}$ Laboratoire de Géologie, Ecole Normale Supérieure / CNRS UMR 8538, PSL Research

8 University, 24 rue Lhomond, 75005, Paris, France.

$9{ }^{2}$ Woods Hole Oceanographic Institution, 266 Woods Hole Rd., Woods Hole MA, 02543, USA.

$10{ }^{3}$ Now at: Scripps Institution of Oceanography, Institute of Geophysics and Planetary Physics,

11 University of California, San Diego, La Jolla, CA 92093, USA

$12{ }^{4}$ Institut de Physique du Globe de Paris - CNRS UMR 7154, 1 rue Jussieu, 75005, Paris,

13 France.

$14{ }^{5}$ National Science Foundation, 2415 Eisenhower Ave., Alexandria, VA, 22314, USA.

$15{ }^{6}$ GEOMAR / Helmholtz Centre for Ocean Research, Wischhofstrasse 1-3, 24148, Kiel, Germany.

17 *Corresponding author: olive@geologie.ens.fr

\section{Keywords}

20 Mid-ocean ridge; detachment faulting; oceanic core complex; critical taper; fault friction;

\section{Highlights}

23 - A small fraction of corrugated detachment fault surfaces is eventually exposed at the seafloor.

24 - Seafloor slopes indicate effective friction of $\sim 0.15$ on shallow part of detachments.

25 - Moderate-offset detachment faults may be largely blanketed by hanging wall material.

26 - Seafloor-shaping processes profoundly alter the morphology of oceanic core complexes. 
Abstract

30 While oceanic detachment faults have been proposed to account for the accretion of $\sim 40 \%$ of new seafloor in the North Atlantic ocean, clear exposures of large-offset, often-corrugated fault surfaces remain scarce and spatially limited. To help resolve this paradox, we examine the conditions under which detachment fault growth may or may not lead to extensive exposure of corrugated fault planes at the seafloor. Using high-resolution bathymetry from four detachment faults at the northern Mid-Atlantic Ridge, we investigate the rafting of hanging wall-derived debris over emerging fault scarps, which can lead to covering shallow-dipping corrugated fault surfaces. We model this process using critical taper theory, and infer low effective friction coefficients $(\sim 0.15)$ on the shallowest portion of detachment faults. A corollary to this result is that detachments emerging from the seafloor at angles $<10^{\circ}$ are more likely to become blanketed under an apron of hanging wall material. We generalize these findings as a simple model for the progressive exposure and flexural rotation of detachment footwalls, which accounts for the continued action of seafloorshaping processes. Our model suggests that many moderate-offset, hidden detachment faults may exist along slow mid-ocean ridges, and do not feature an exposed fault surface.

Bathymetric highs composed of mafic and ultramafic units are a characteristic feature of slowly accreted seafloor. These massifs are often capped by corrugated slip surfaces that represent the rotated footwalls of detachment faults with offsets on par with or greater than the thickness of young oceanic lithosphere (Cann et al., 1997; Tucholke et al., 1998; Parnell-Turner et al., 2018). These faults are generally found on ridge sections characterized by greater-than-average seismicity rates, lava geochemistry indicative of deeper fractionation, and hydrothermal activity (deMartin et al., 2007; McCaig et al., 2007; Escartín et al., 2008b; Blackman et al., 2011; Wilson et al., 2013; Olive and Escartín, 2016). Such observations led Escartín et al. (2008b) to postulate that detachment faulting enables a distinct mode of asymmetric seafloor spreading, favored wherever the magma supply of a mid-ocean ridge is subdued (Buck et al., 2005; Tucholke et al., 2008; Olive et al., 2010).

Significant portions of seafloor in the North Atlantic ocean are presently forming through asymmetric spreading (Escartín et al., 2008b; Cann et al., 2015). However, seafloor exposures 
spatially confined ( $\leq 10 \mathrm{~km}$ along-axis; Fig. 1 ) and only make up a small fraction of the $>40 \mathrm{~km}-$

61 long asymmetric sections of slow-spreading ridges. One explanation may be that detachment faults

62 underlie entire ridge segments but are only exposed in areas where hanging wall rider blocks

63 cannot develop (Smith et al., 2008; Reston and Ranero, 2011). Another is that detachment faults

64 have a limited along-axis extent and connect with shorter-offset faults through complex relay 65 structures (Smith et al., 2008; Tian and Choi, 2017). This debate warrants an improved 66 understanding of how various seafloor-shaping processes modulate the exposure of pristine slip 67 surfaces during detachment fault growth. These processes include gravitational mass wasting, which can both erode and cover portions of the footwall (Cannat et al., 2013), as well as rafting of

69 hanging wall material onto the footwall. Here we investigate the mechanical and geometrical

70 factors that lead to covering an emerging detachment surface under a hanging wall apron, making 71 large-offset fault surfaces difficult to detect in shipboard bathymetric data. We then assess the 72 relative impact of hanging wall rafting and mass wasting on the shape of oceanic detachment faults.

\section{Seafloor morphology near oceanic detachment faults}

Fig. 1 shows high-resolution $(<2 \mathrm{~m})$ bathymetry acquired using autonomous underwater vehicles at four detachment faults along the Northern Mid-Atlantic Ridge: 13²0'N (Escartín and Petersen, 2017; Escartín et al., 2017), 16³6'N and South Core Complex (SCC; Smith et al., 2014), and the Trans-Atlantic Geotraverse (TAG) detachment (Petersen et al., 2016). Geological interpretations of bathymetric features and textures, combined with in-situ observations at $13^{\circ} 20^{\prime} \mathrm{N}$, suggest a common sequence of morphological domains at these detachments. The footwall cut-off scarp (i.e., the breakaway high marking the initial location of fault emergence) is often texturally rough

82 (e.g., Fig. 1C), which is interpreted as the result of extensive gravitational mass wasting (Escartín 83 et al., 2017). Towards the ridge axis, this chaotic terrain gradually transitions into the corrugated 84 fault surface (Fig. 1A-D). This transition marks the place where angular blocks and talus stripped 85 from the breakaway ridge no longer blanket freshly exposed corrugated fault surfaces. This 86 difference is likely because the initially steep surface of growing detachments eventually rotates 87 to gravitationally stable angles $\left(<30^{\circ}\right.$, Lavier et al., 1999), which are no longer prone to mass wasting (Cannat et al., 2013; Smith et al., 2014; Escartín et al., 2017).

The spatial extent of exposed corrugated surfaces varies greatly from one detachment to 
91 and abruptly connects with a rougher region termed "apron", axis-ward of the bathymetric moat 92 that marks the fault termination or hanging wall cut-off (break in slope in Fig. 2). At $13^{\circ} 20^{\prime} \mathrm{N}$ the 93 apron consists of basaltic and diabase blocks in an unlithified matrix, and incorporates some

94 footwall-derived peridotite and gabbro (Escartín et al., 2017). The apron surface has a texture that 95 is distinct from the adjacent volcanic terrain covering the ridge axis, and in many instances is thin 96 enough for the underlying corrugations to be visible beneath (Fig. 1A-D; Fig. 3A). At TAG, the 97 apron spans an area wider than the corrugated surface (Fig. 1A), and is directly adjacent to the 98 chaotic terrain south of $26^{\circ} 09^{\prime} \mathrm{N}$. This geometry suggests that the apron has the potential to blanket 99 large extents of the detachment surface when certain geometrical and rheological conditions are 100 met.

\section{Detachment aprons as extensional Coulomb wedges}

103 To understand how hanging wall material may be dragged onto the emerging fault surface, we 104 model the apron as a cohesionless, critical Coulomb wedge of seafloor slope $\alpha$ with friction angle $105 \phi_{0}\left(30^{\circ}\right.$, appropriate for mafic lithologies) overlying a detachment fault of $\operatorname{dip} \beta$ and friction angle $\phi_{D}$ (Fig. 3A, Davis et al., 1983; Dahlen, 1984; Xiao et al., 1991; Yuan et al., 2015). We specifically 107 use the critical wedge model of Yuan et al. (2015), which accounts for the possibility of fluid 108 overpressure in the detachment. The fundamental assumption of wedge models is that the state of stress in the apron results from a balance between topographic and frictional forces and is on the

110 verge of failure everywhere in critical wedges. The assumption of a cohesionless material is 111 consistent with observations of the $13^{\circ} 20^{\prime} \mathrm{N}$ detachment suggesting that the apron consists of a 112 mixture of unconsolidated rubble and finer-grained materials (Escartín et al., 2017).

113 We describe the state of stress within the wedge using two quantities $\psi_{D}$ and $\psi_{0}$, which 114 denote the angles between the most compressive principal stress $\left(\sigma_{l}\right)$ and the detachment and apron 115 surface, respectively. These are useful to determine potential slip lines within the apron, which are 116 expected to lie at $\left( \pm 45^{\circ}-\phi_{0} / 2\right)$ from $\sigma_{l}$ (Fig. 3A). By definition, the critical taper angle for the apron 117 verifies:

$$
\alpha+\beta=\psi_{D}-\psi_{0} .
$$

119 If the entire apron is on the verge of Mohr-Coulomb failure, then only certain values of $\alpha, \psi_{D}$ and $120 \psi_{0}$ are admissible for a given $\beta$. These values verify the following set of implicit equations: 


$$
\frac{\sin \alpha^{\prime}}{\sin \phi_{0}}-\sin \left(2 \psi_{0}+\alpha^{\prime}\right)=0
$$

122

124

125

126

127

128

129 with

and

$$
\sin \left(2 \psi_{D}+\phi_{D}\right)-\frac{1-\lambda_{D}}{1-\lambda_{0}} \frac{\sin \phi_{D}}{\sin \phi_{0}}-\frac{\lambda_{D}-\lambda_{0}}{1-\lambda_{0}} \sin \phi_{D} \cos 2 \psi_{0}=0 .
$$

In equation (2), $\alpha^{\prime}$ is defined as an angle verifying

$$
\tan \alpha^{\prime}=\frac{1-\rho_{f} / \rho}{1-\lambda_{0}} \tan \alpha
$$

where $\lambda_{0}$ and $\lambda_{D}$ denote the fluid pressure ratio in the apron and detachment, respectively. The fluid pressure ratio is defined following Yuan et al. (2015) as

$$
\lambda=-\frac{p f-\rho_{f} g D}{\sigma_{z}+\rho_{f} g D}
$$

$$
\sigma_{z}=-\rho g z \cos \alpha-\rho_{f} g D .
$$

In equations (5) and (6), $p_{f}$ is fluid pressure at a point located at a seafloor-normal distance $z$ beneath the apron surface (notation "D2" in Yuan et al., 2015). $D$ is the water depth, and $\rho$ and $\rho_{f}$ refer to the density of the apron material $\left(2400 \mathrm{~kg} \mathrm{~m}^{-3}\right)$ and of the fluid percolating within the apron $\left(1000 \mathrm{~kg} \mathrm{~m}^{-3}\right)$. We assume that seawater easily percolates into the heavily damaged apron (Escartin et al., 2017), and exerts a hydrostatic fluid pressure throughout the wedge, i.e., fluid pressure increases downward in the wedge following a hydrostatic gradient. It can be shown that equation (5) reduces to $\lambda=\rho_{f} / \rho$ under hydrostatic conditions (see Appendix A. of Yuan et al. 2015). The fluid pressure ratio is thus set equal to 0.42 within the apron for the remainder of our study.

Equations (1-3) are formulated in terms of a residual function $F\left(\alpha, \psi_{D}, \psi_{0}\right)=0$, and solved with a Newton method for a range of $\beta$-values. The associated Jacobian $\nabla F$ is estimated using centered finite difference with a step of $10^{-6} \mathrm{rad}$. Convergence is considered achieved when the norm of the residual falls below $10^{-11}$. Our initial guess is $\alpha=\phi_{0} / 2, \psi_{0}=20^{\circ}$, and $\psi_{D}$ set to either $20^{\circ}$ or $120^{\circ}$, which are empirically found to promote convergence towards the upper or lower branch of the envelope, respectively. For a given pair of fault friction and fault fluid pressure values -which can be expressed as an effective fault friction $\mu_{\text {eff }}$ (Fig. 3A) - the slope of the apron and the dip of the detachment must satisfy a set of equilibrium relations, plotted as stability envelopes in Fig. 3B. A MATLAB ${ }^{\odot}$ script GetWedgeEnvelope.m is provided as part of the Supplementary Materials to generate stability envelopes (combinations of $\alpha$ and $\beta$ ) as a function 
of $\phi_{0}, \phi_{D}, \lambda_{0}$, and $\lambda_{D}$. This function calls the subroutines wedge_residual.m (Residual function) and wedge_jacobianFD.m (Jacobian approximation), which are also provided.

Estimates for apron slope and detachment fault dip were obtained along 89 profiles oriented parallel to the spreading direction, crossing the hanging-wall cutoff (or moat; see Fig. 2 and 3A). High-resolution bathymetry was extracted along profiles spaced $100 \mathrm{~m}$ apart at the four study locations (Fig. 1). The position of the hanging-wall cutoff and spatial extent of the moat was identified in map-view, based upon the locus of change in bathymetric slope, and then used to define the hanging wall, footwall, and moat sections along each profile (Fig. 2). The mean apron slope was estimated for each profile using the slope of a linear least-squares fit to the bathymetry calculated over a $500 \mathrm{~m}$ distance downslope from the hanging wall-side edge of the moat, hence the moat itself is not included in the fit. The mean detachment fault dip was estimated using the slope of a linear fit to the bathymetry calculated $800 \mathrm{~m}$ upslope from the footwall-side edge of the moat. Uniform fitting lengths were chosen for consistency and to minimize the effects of local changes in slope, while not allowing profiles to extend onto the chaotic or neovolcanic terrains. The average apron slope across our detachments is $6.2 \pm 3.3^{\circ}$ ( 1 standard deviation), and the average detachment dip right beneath the hanging wall cutoff is $13.8 \pm 2.5^{\circ}$.

\section{Low effective friction on the shallow part of oceanic detachment faults}

We follow a grid search approach to identify the value of $\mu_{\text {eff }}$ that best explains the observed pair of $(\alpha, \beta>-\alpha)$ along 89 corrugation-parallel bathymetric transects at the four detachments shown in Figs. 1 and 2. For each pair $(\alpha, \beta)$, we construct 100 envelopes spanning values of $0.42 \leq \lambda_{D} \leq$ 0.82 and $0 \leq \phi_{D} \leq 30^{\circ}$. Each point on these envelopes corresponds to a specific stress orientation, which determines the orientation of possible slip lines (secondary faults) within the apron (Fig. 3A). We restrict our analysis to the upper branch of the envelopes, which predicts net extension in the wedge. We retain the envelopes whose upper branch lies at the shortest distance to each $(\alpha, \beta)$ pair, within an error of $2^{\circ}$ (Fig. 3B). This set of best-fitting envelopes correspond to a narrow subset of $\left(\lambda_{D}, \phi_{D}\right)$ space, and consequently to a narrow range of $\mu_{e f f}$ values. We repeat this operation for an entire grid of $(\alpha, \beta)$ values, to which we are able to assign a best fitting $\mu_{\text {eff }}$ with a typical error of \pm 0.01 , plotted in Fig. 4 and as colored dots for each profile in Fig. 1. For convenience, we also 
179

provide a polynomial approximation for $\mu_{\text {eff }}$ as a function of $(\alpha, \beta)$, in degrees, which is accurate within the above error margin:

$$
\begin{aligned}
& \mu_{\text {eff }}=0.008252+0.004973 \beta-0.003603 \alpha \\
& +0.00012 \beta^{2}+1.026 \times 10^{-5} \alpha \beta+7.116 \times 10^{-5} \alpha^{2} \\
& -1.853 \times 10^{-6} \beta^{3}+3.793 \times 10^{-7} \beta^{2} \alpha-3.959 \times 10^{-6} \beta \alpha^{2} \\
& -2.385 \times 10^{-6} \alpha^{3}
\end{aligned}
$$

The inversion procedure described above yields a range of $\mu_{\text {eff }}$ between 0.06 and 0.16 , with a mode at 0.14 (Fig. 4). Since the geometry of the detachment surface is concave-down, measuring fault dip at the termination may underestimate the true dip of the detachment beneath the apron region (Fig. 3A). Estimates of the sub-seafloor fault geometry (available only for TAG and $13^{\circ} 20^{\prime} \mathrm{N}$ : deMartin et al., 2007; Parnell-Turner et al., 2017) suggest that detachments may steepen by at most $\sim 10^{\circ}$ across the apron (see section 5). Underestimating the average detachment dip beneath the apron by $\sim 5^{\circ}$ would lead to underestimating the effective friction by $\sim 0.04$. Fig. 4 provides a straightforward way to assess the effect of an underestimated detachment dip (e.g., by translating the points towards the right by $\sim 5^{\circ}$ ).

Profiles located away from the center of detachments tend to yield lower $\mu_{\text {eff }}$ (Fig. 1), which may be due to the termination strike being highly oblique to the spreading direction at these locations owing to the three-dimensional fault morphology. By contrast, profiles oriented normal to the termination (i.e., most compatible with the two dimensional nature of the critical wedge model and often located in the central part of the detachment) commonly yield $\mu_{e f f}$ values ranging between 0.10 and 0.16, which we consider to be more reliable. Some short-wavelength apparent variability in $\mu_{\text {eff }}$ directly reflects second-order tectonic features that offset the fault termination and alter slopes (e.g., at SCC, N and S of $16.425^{\circ} \mathrm{N}$, Fig. 1B). Our 2-D analysis is therefore unlikely to resolve frictional heterogeneities on a given detachment, if present.

Low values of effective friction are consistent with the common inference that the low strength of detachment faults enables their longevity (Escartín et al., 1997). Our strength estimates are however only representative of the uppermost $\sim 1 \mathrm{~km}$ portion of detachments, which may be different from the rest of the fault. A possible manifestation of this difference could be the lack of shallow $(\leq 3 \mathrm{~km})$ microseismicity beneath TAG (deMartin et al., 2007) and $13^{\circ} 20^{\prime} \mathrm{N}$ (ParnellTurner et al., 2017), as recorded by local ocean bottom seismometers (OBS) arrays. While low effective friction on compressional décollements is typically attributed to elevated fluid pressure 
207 (e.g., Dahlen, 1984), such a scenario may be harder to envision in a tensional regime where cracks 208 and pores are likely well connected. If fluid pressure is hydrostatic within the detachment fault 209 zone, as was inferred by Hansen et al. 2013 for the Kane detachment down to depths of $\sim 5 \mathrm{~km}$, 210 then the true friction coefficient of the fault material must lie between $\sim 0.17$ and $\sim 0.26$ (Fig. 3A). 211 The precipitation of very weak minerals such as talc, with friction coefficients ranging between $212 \sim 0.05$ and 0.23 (Moore and Lockner, 2008; Escartín et al., 2008a) in the fault zone has been 213 invoked as a key contributor to long-term strain localization (Escartín et al., 1997). By contrast, 214 invoking moderately weak clay minerals (with friction coefficients of $\sim 0.4$, e.g., Tesei et al., 2012) 215 to explain our estimates of effective friction would however require super-hydrostatic fluid 216 pressure ratios between 0.6 and 0.75 . The $13^{\circ} 20^{\prime} \mathrm{N}$ detachment, however, does not feature extensive 217 weak phases (e.g., serpentinite, talc) and instead shows pervasive silicification (Bonnemains et al., 218 2017). The low effective friction of detachments may instead have a non-lithological origin. 219 Episodes of seismic slip have been documented in the shallow, microseismically quiet portion of 220 the $13^{\circ} 20^{\prime} \mathrm{N}$ detachment (Craig and Parnell-Turner, 2017). It is possible that infrequent 221 earthquakes catastrophically reshape apron slopes to balance the low shear stresses that prevail 222 during seismic rupture. The temporally-averaged apron slopes we measure may thus be influenced 223 both by the long-term and the short-term fault strength, although this hypothesis is difficult to 224 evaluate with the available data.

225 The above reasoning relies on the assumption that the apron wedge is critically stable, i.e., 226 sits on the stability envelope as shown in Fig. 3B. At the $13^{\circ} 20^{\prime} \mathrm{N}$ detachment, small escarpments 227 are visible in apron topography, potentially indicating secondary faulting (Fig. 3A). Internal wedge 228 deformation alone would be indicative of the unstable wedge regime (outside of the stability 229 envelope, Xiao et al., 1991). When coincident with slip on the detachment, secondary faulting 230 implies a critically-stable apron at $13^{\circ} 20^{\prime} \mathrm{N}$. However, slip on other detachments may occur without 231 faulting in the apron. Such systems would plot inside the stability envelope. Since increasing 232 detachment friction shifts the stability boundary towards greater detachment dips (Hayman et al. 233 2003), one can identify the greatest value of detachment friction that allows a wedge of a given $(\alpha$, $234 \beta$ ) to remain inside the stability envelope. This value corresponds to the critically-stable 235 configuration. In other words, the effective friction determined with our approach must be thought 236 of as an upper-bound on detachment strength. 


\section{Implications for the seafloor exposure of detachment fault surfaces}

Regardless of the mechanistic interpretation for $\mu_{e f f}$, Coulomb wedge theory does predict an effective value for detachment friction that explains apron architecture (including the pattern of secondary faulting: Fig. 3A). A corollary to this model is that a detached piece of apron would not

244 remain affixed to the footwall if the fault emerges from the seafloor with a slope greater than $\tan ^{-}$

$24{ }^{1}\left(\mu_{e f f}\right) \sim 6-9^{\circ}$, because the low basal shear stresses would not be able to counteract gravity. Pieces 246 of apron would thus slide back towards the hanging wall instead of blanketing the footwall.

247 Conversely, a detachment fault emerging from the seafloor with a slope $<9^{\circ}$ should be extensively 248 covered by hanging wall material.

249 The primary challenge in testing this idea is to infer detachment fault dip where it is not 250 exposed. Such estimates are possible at TAG and $13^{\circ} 20^{\prime} \mathrm{N}$, which constitute low and high end251 members for the extent of the corrugated fault surface, respectively, and have both been 252 instrumented with OBS arrays to illuminate the deeper portions of the fault zone through 253 microseismicity (deMartin et al., 2007; Parnell-Turner et al., 2017). The clouds of extensional 254 microseismicity observed at the roots of TAG and $13^{\circ} 20^{\prime} \mathrm{N}$ show dips as large as $70^{\circ}$ at depths of $255 \sim 7 \mathrm{~km}$ below seafloor. This clearly indicates an overall concave-down geometry of the detachment 256 at depth. High-resolution seismic imaging studies will be needed to improve our knowledge of the 257 near-surface geometry of these detachments. In the meantime, seafloor slopes reveal that a large 258 portion of the apron domain at TAG is underlain by a detachment dipping with angles $\leq 10^{\circ}$ (Fig. $2592 \mathrm{~A}$ ), which is not the case at $13^{\circ} 20^{\prime} \mathrm{N}$, where the fault emerges with slopes of $\sim 15^{\circ}$ (Fig. 2D). This 260 simple comparison supports the idea that a gently dipping detachment is prone to extensive 261 blanketing by apron material, and less likely to feature extensive, well exposed corrugated 262 surfaces.

6. From covered to exposed detachment surfaces

266 along slopes with an angle of repose steeper than $20-30^{\circ}$ (Cannat et al., 2013). By contrast, 267 blanketing of exposed fault surfaces by hanging wall material is favored for shallow slopes $<10^{\circ}$. 268 The emerging slope of a detachment fault is known to change as the footwall undergoes flexural 
re-adjustment with continued slip (Buck, 1988; Lavier et al., 1999; Morris et al., 2009). Fig. 5

270 illustrates this process using an elastic model for footwall topography with increasing fault offset

271 (Buck, 1988; Schouten et al., 2010; Olive and Behn, 2014). In the early stages of detachment

272 growth, a breakaway ridge forms by slip along a high angle $\left(>30^{\circ}\right)$ fault, which triggers the 273 extensive mass wasting that shapes the chaotic terrain (Fig. 5A). The morphology of young 274 detachments may thus be strongly determined by the competition between the rate of footwall 275 degradation by repeated rockslides, and the fault slip rate. Hence, efficient mass wasting could 276 very well bury short-offset corrugated surfaces under footwall-derived debris.

277 As fault offset increases, flexural rotation decreases the emerging detachment slope until 278 it becomes sub-horizontal (Fig. 5B). This stage favors extensive blanketing of the corrugated fault 279 surface by hanging wall material, as seen today at TAG, a detachment fault with only $\sim 5 \mathrm{~km}$ of 280 offset (deMartin et al., 2007). Further extension on the detachment drives footwall doming (Fig. 281 5C), which increases the slope of the emerging footwall $\left(>10^{\circ}\right)$ and shrinks the apron domain, 282 revealing an extensive corrugated surface (e.g., $13^{\circ} 20^{\prime} \mathrm{N}$, with $9 \mathrm{~km}$ of offset). It should be noted 283 that the emergence angle will to some extent also reflect the amount of volcanic material extruded 284 onto the hanging wall (magmatic accretion in Fig. 5A).

285 Our model suggests that moderate-offset detachment faults may be widespread along slow286 spreading ridges but remain undetected by shipboard bathymetric surveys, as they are largely 287 blanketed by hanging wall material and do not (yet) expose large corrugated surfaces at the 288 seafloor. Extensive high-resolution bathymetric surveys and a better mechanistic description of 289 seafloor-shaping processes thus constitute crucial next steps to improve our understanding of slow290 spreading ridge tectonics.

\section{Acknowledgements}

293 The authors wish to thank the ODEMAR (doi:10.17600/13030070) and M127 Science Parties as 294 well as the teams operating the AUVs (WHOI's Sentry and GEOMAR's Abyss). JAO was funded 295 under NSF project EAR16500166. Cruise funding was provided through CNRS and IFREMER 296 (JE), and GEOMAR and the EU-FP7-Project "Blue Mining: Breakthrough Solutions for the 297 Sustainable Exploration and Extraction of Deep Sea Mineral Resources" under grant No. 604500 298 (SP). Xiaoping Yuan provided valuable guidance on the Coulomb wedge modeling. Finally, we 
299 thank Nadaya Cubas, Nicholas Hayman, and an anonymous reviewer for their thoughtful 300 suggestions, which greatly improved our manuscript.

\section{References}

Blackman, D.K., et al., 2011, Drilling constraints on lithospheric accretion and evolution at Atlantis Massif, Mid-Atlantic Ridge $30^{\circ} \mathrm{N}$ : J. Geophys. Res., v. 116, no. B07103, doi:10.1029/2010JB007931.

Bonnemains, D., Escartín, J., Mével, C., Andreani, M., and Verlaguet, A., 2017, Pervasive silicification and hanging wall overplating along the $13^{\circ} 20^{\prime} \mathrm{N}$ oceanic detachment fault (MidAtlantic Ridge): Geochem. Geophys. Geosyst., v. 18, no. 6, p. 2028-2053, doi:10.1002/2017GC006846.

Buck, W.R., 1988, Flexural Rotation of Normal Faults: Tectonics, v. 7, no. 5, p. 959-973, doi: 10.1029/TC007i005p00959.

Buck, W.R., Lavier, L., and Poliakov, A.N.B., 2005, Modes of faulting at mid-ocean ridges: Nature, v. 434, p. 719-723, doi: 10.1038/nature03358.

314 Cann, J.R., Blackman, D.K., Smith, D.K., McAllister, E., Janssen, B., Mello, S., Avgerinos, E., Pascoe, A.R., and Escartin, J., 1997, Corrugated slip surfaces formed at North Atlantic ridge-

Cann, J.R., Smith, D.K., Escartín, J., and Schouten, H., 2015, Tectonic evolution of $200 \mathrm{~km}$ of transform intersections: Nature, v. 385, p. 329-332.

Cannat, M., Mangeney, A., Ondréas, H., Fouquet, Y., and Normand, A., 2013, High-resolution bathymetry reveals contrasting landslide activity shaping the walls of the Mid-Atlantic Ridge axial valley: Geochem., Geophys., Geosyst., v. 14, no. 4, p. 996-1011, http://doi.org/10.1002/ggge.20056. 
Craig, T.J., Parnell-Turner, R., 2017. Depth-varying seismogenesis on an oceanic detachment fault at $13^{\circ} 20^{\prime} \mathrm{N}$ on the Mid-Atlantic Ridge. Earth Planet. Sci. Lett., v. 479, p. 60-70, doi:10.1016/j.eps1.2017.09.020.

Dahlen, F.A., 1984, Noncohesive critical Coulomb wedges: An exact solution: J. Geophys. Res., Collins, J.A., Smith, D.K., and Mcguire, J.J., 2012, Seismicity of the Atlantis Massif detachment fault, $30^{\circ} \mathrm{N}$ at the Mid-Atlantic Ridge: Geochem. Geophys. Geosyst., v. 13, no. 1, p. doi:10.1029/2012GC004210, doi: 10.1029/2012GC004210.

Davis, D., Suppe, J., and Dahlen, F.A., 1983, Mechanics of fold-and-thrust belts and accretionary wedges: J. Geophys. Res., v. 88, no. B2, p. 1153-1172.

deMartin, B. J., Sohn, R.A., Canales, J.P., and Humphris, S.E., 2007, Kinematics and geometry of active detachment faulting beneath the Trans-Atlantic Geotraverse (TAG) hydrothermal field on the Mid-Atlantic Ridge: Geology, v. 35, p. 711-714, doi: 10.1130/G23718A.1.

Escartín, J., Hirth, G., and Evans, B., 1997, Effects of serpentinization on the lithospheric strength and the style of normal faulting at slow-spreading ridges: Earth Planet. Sci. Lett., v. 151, no. 3-4, p. 181-189, doi:10.1016/S0012-821X(97)81847-X.

Escartín, J., Andreani, M., Hirth, G., and Evans, B., 2008a, Relationships between the microstructural evolution and the rheology of talc at elevated pressures and temperatures: Earth Planet. Sci. Lett., v. 268, p. 463-475.

Escartín, J., and Petersen, S., 2017, ODEMAR AUV Abyss (GEOMAR) + shipboard Pourquoi

Escartín, J., Smith, D.K., Cann, J.R., Schouten, H., Langmuir, C.H., and Escrig, S., 2008b, Central role of detachment faults in accretion of slow-spreading oceanic lithosphere: Nature, v. 455, no. 7214, p. 790-794, doi: 10.1038/nature07333.

Pas? Multibeam bathymetry $-13^{\circ} 20^{\prime} \mathrm{N}$ and $13^{\circ} 30^{\prime} \mathrm{N}$ Oceanic Core Complexes, Mid-Atlantic Ridge: SEANOE, http://doi.org/10.17882/48335. 
353 Escartín, J., Petersen, S., Bonnemains, D., Cannat, M., Andreani, M., Bezos, A., Chavagnac, V., 354 Choi, Y., Godard, M., Haaga, K., Hamelin, C., Ildefonse, B., Jamieson, J., John, B., et al.,

Hansen, L.N., Cheadle, M.J., John, B.E., Swapp, S.M., Dick, H.J.B., Tucholke, B.E., and Tivey, M.A., 2013, Mylonitic deformation at the Kane oceanic core complex: Implications for the rheological behavior of oceanic detachment faults: Geochem. Geophys. Geosyst., 14, doi:10.1002/ggge.20184.

Hayman, N.W., Knott, J.R., Cowan, D.S., Nemser, E., and Sarna-Wojnicki, A.M., 2003, Quaternary low-angle slip on detachment faults in Death Valley, California: Geology, v. 31, no. 4 , p. 343-346.

Lavier, L., Buck, W.R., and Poliakov, A., 1999, Self-consistent rolling-hinge model for the evolution of large-onset low-angle normal faults: Geology, v. 27, no. 12, p. 1127-1130, doi: 10.1130/0091-7613(1999)027<1127:SCRHMF>2.3.CO;2.

McCaig, A.M., Cliff, R.A., Escartín, J., Fallick, A.E., and MacLeod, C.J., 2007, Oceanic detachment faults focus very large volumes of black smoker fluids: Geology, v. 35, no. 10., p. 935-938.

Moore, D.E., and Lockner, D.A., 2008, Talc friction in the temperature range $25^{\circ}-400^{\circ} \mathrm{C}$ : Relevance for fault-zone weakening: Tectonophysics, v. 449, p. 120-132, doi:10.1016/j.tecto.2007.11.039.

Morris, A., Gee, J.S., Pressling, N., John, B.E., MacLeod, C.J., Grimes, C.B., and Searle, R.C., 2009, Footwall rotation in an oceanic core complex quantified using reoriented Integrated Ocean Drilling Program core samples: Earth Planet. Sci. Lett., v. 287, no. 1-2, p. 217-228, doi: 10.1016/j.epsl.2009.08.007.

Olive, J.-A., Behn, M.D., and Tucholke, B.E., 2010, The structure of oceanic core complexes controlled by the depth-distribution of magma emplacement: Nat. Geosci., v. 3., p. 491-495, 
doi:10.1038/ngeo888.

381 Olive, J.-A., and Behn, M.D., 2014, Rapid rotation of normal faults due to flexural stresses: An 382 explanation for the global distribution of normal fault dips: J. Geophys. Res., 119, 383 doi:10.1002/2013JB010512.

Olive, J.-A., and Escartín, J., 2016, Dependence of seismic coupling on normal fault style along the Northern Mid-Atlantic Ridge: Geochem. Geophys. Geosyst., 17, 4128-4152, doi:10.1002/

Parnell-Turner, R., Escartín, J., Olive, J.A., Smith, D.K., Petersen, S., 2018. Genesis of corrugated fault surfaces by strain localization recorded at oceanic detachments. Earth Planet. Sci. Lett.

Parnell-Turner, R., Sohn., R.A., Peirce, C., Reston, T.J., MacLeod, C.J., Searle, R.C., and Simão, 498, 116-128. doi:10.1016/j.eps1.2018.06.034

Petersen, S., and Shipboard Scientific Party, 2016, Cruise report M127-Metal fluxes and Resource Potential at the Slow-spreading TAG Mid-ocean Ridge Segment (26 N, MAR)- Blue

Reston, T.J., and Ranero C.R., 2011, The 3-D geometry of detachment faulting at mid-ocean ridges: Geochem. Geophys., Geosyst., v. 12, no. 7, doi:10.1029/2011GC003666.

Schouten, H., Smith, D.K., Cann, J.R., and Escartin, J., 2010, Tectonic versus magmatic extension Mining@Sea: GEOMAR report 32, doi: 10.3289/GEOMAR_REP_NS_32_2016. 
(Mid-Atlantic Ridge, $13^{\circ}-15^{\circ} \mathrm{N}$ ): Geochem. Geophys. Geosyst., v. 9, no. 3, p. doi:10.1029/2007GC001699, doi: 10.1029/2007GC001699.

411 Smith, D.K., Schouten, H., Dick, H.J.B., Cann, J.R., Salters, V., Marschall, H.R., Ji, F., Yoerger, 412 D., Sanfilippo, A., Parnell-Turner, R., Palmiotto, C., Zheleznov, A., Bai, H., Junkin, W., et al., 2014, Development and evolution of detachment faulting along $50 \mathrm{~km}$ of the Mid-Atlantic Ridge near $16.5^{\circ} \mathrm{N}$ : Geochem. Geophys. Geosyst., v. 15, p. 4692-4711, doi:10.1002/2014GC005563.

Spencer, J.E., Reynolds, S.J., Scott, R.J., and Richard, S.M., 2016, Shortening in the upper plate of the Buckskin-Rawhide extensional detachment fault, southwestern U.S., and implications for stress conditions during extension: Tectonics, v. 35, no. 12, p. 3119-3136, doi:10.1002/2016TC004345.

Tesei, T., Collettini, C., Carpenter, B.M., Viti, C., and Marone, C., 2012, Frictional strength and healing behavior of phyllosilicate-rich faults: J. Geophys. Res., v. 117, doi:10.1029/2012JB009204.

Tian, X., and Choi, E., 2017, Effects of axially variable diking rates on faulting at slow spreading mid-ocean ridges: Earth Planet. Sci. Lett., v. 458, p. 14-21.

Tucholke, B.E., Lin, J., and Kleinrock, M.C., 1998, Megamullions and mullion structure defining oceanic metamorphic core complexes on the Mid-Atlantic Ridge: J. Geophys. Res., v. 103, no. B5, p. 9857-9866.

Xiao, H.-B., Dahlen, F.A., and Suppe, J., 1991, Mechanics of extensional wedges: J. Geophys.

Wilson, S.C., Murton, B.J., and Taylor, R.N., 2013, Mantle composition controls the development of an Oceanic Core Complex: Geochem. Geophys. Geosyst., v. 14., no. 4, doi: 10.1002/ggge.20046

Yuan, X.P., Leroy, Y.M., and Maillot, B., 2015, Tectonic and gravity extensional collapses in overpressured cohesive and frictional wedges: J. Geophys. Res., v. 120, 
435 doi:10.1002/2014JB011612.

436 


\section{Figure captions}

439 Figure 1. A-D: Seafloor terrain and slopes at four Mid-Atlantic Ridge detachment faults (locations 440 shown in inset E), from AUV bathymetric data gridded at $2 \mathrm{~m}$ resolution and plotted at equal scale. 441 Colored dots mark detachment termination, color-coded by effective friction (see section 4). Red 442 arrows indicate spreading direction, pointing away from the ridge axis. Dashed lines show 443 northernmost and southernmost spreading-parallel profiles bracketing topographic profiles used 444 here, which are evenly spaced at $100 \mathrm{~m}$. RR = rubble ridges, i.e., small fragments of broken-down 445 apron carried by the fault surface.

447 Figure 2. High-resolution bathymetric profiles oriented parallel to the transport direction (inferred 448 from corrugations), spaced $100 \mathrm{~m}$ apart between dashed lines in Fig. 1. Thin red/blue/black 449 sections are hanging wall / footwall / moat sections of each profile, respectively; thick gray lines 450 are linear fits used to obtain estimates for apron slope and detachment fault dip. A: TAG; B: $451 \quad 16^{\circ} 36^{\prime} \mathrm{N}$ OCC; C: South Core Complex; D: $13^{\circ} 20^{\prime} \mathrm{N}$ OCC.

Figure 3. A: Schematic cross section of the termination of the $13^{\circ} 20^{\prime} \mathrm{N}$ detachment fault, based on 454 topographic profile XX' from Fig. 1D. Inset shows a zoom on the hanging wall apron, with inferred 455 slip line orientations. Setup of corresponding critical taper model shown below. B: Stability 456 envelopes calculated using extensional taper model. These envelopes all account for slope of $45713^{\circ} 20^{\prime} \mathrm{N}$ apron measured along crest profile, and all correspond to an effective friction coefficient 458 of $\mu_{\text {eff }}=0.15 \pm 0.01$ on detachment fault.

Figure 4. Contours of best-fitting effective friction on a detachment fault of $\operatorname{dip} \beta$ underlying an apron of slope $\alpha$, assuming a critical taper model with hydrostatic fluid pressure and an internal

462 friction angle of $30^{\circ}$. Symbols indicate measured slopes along the profiles bracketed in Fig. 1. hc: 463 hanging wall cutoff (termination).

Figure 5. Progressive rollover and exhumation of a detachment fault. Blue curve is rolling hinge model of Buck (1988) for an elastic plate of flexural wavelength $L(\sim 1 \mathrm{~km}$ at the MAR, Schouten 
468 to mass wasting of the breakaway (fc: footwall cutoff) region, eventually forming the chaotic 469 terrain. B: At intermediate offsets (e.g., fault heave $=3 L$ ) flexural rotation of the footwall leads to 470 very shallow seafloor slopes, promoting a widespread apron zone burying most of the detachment 471 surface. C: Finally, at large offsets (e.g., fault heave $=4 L$ ) late-stage doming occurs close to the 472 fault termination (hc: hanging wall cutoff) where seafloor slopes increase, reducing the extent of 473 the apron and exposing the corrugated detachment surface (wiggly lines). 


\section{Figure 1}

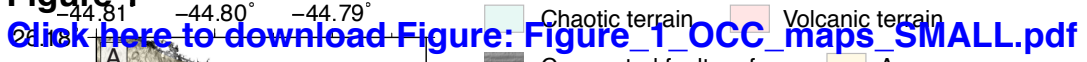

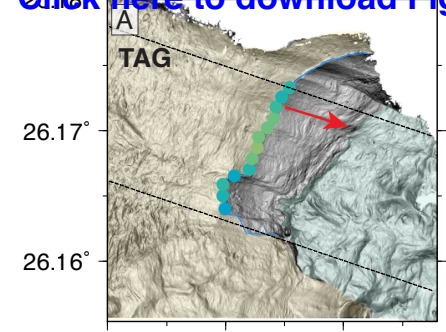

Corrugated fault surface

Apron

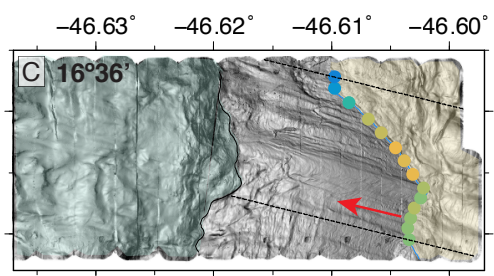

$16.59^{\circ}$
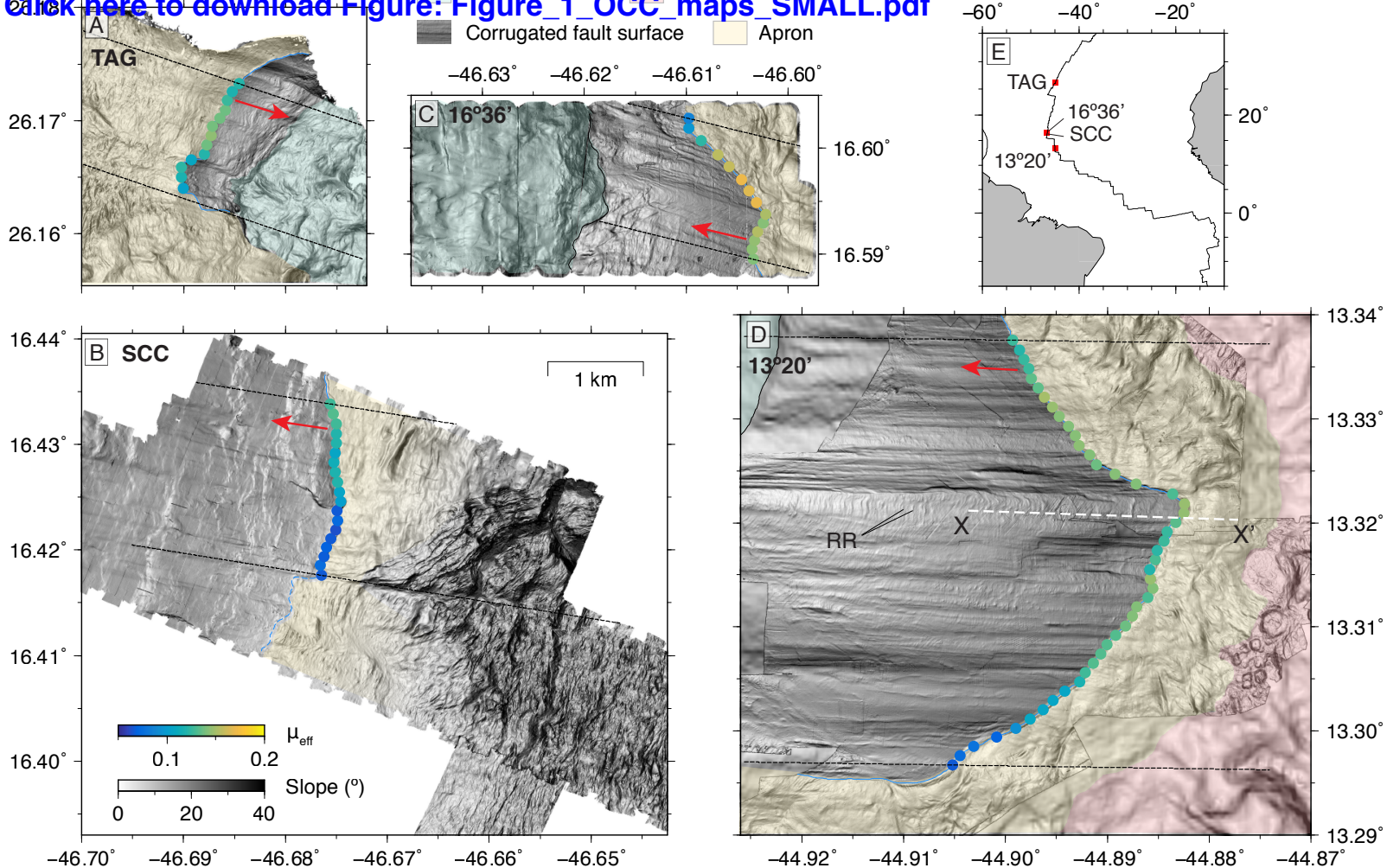
CliA_ here to download Figure: Figure_3_apron_model.pdf

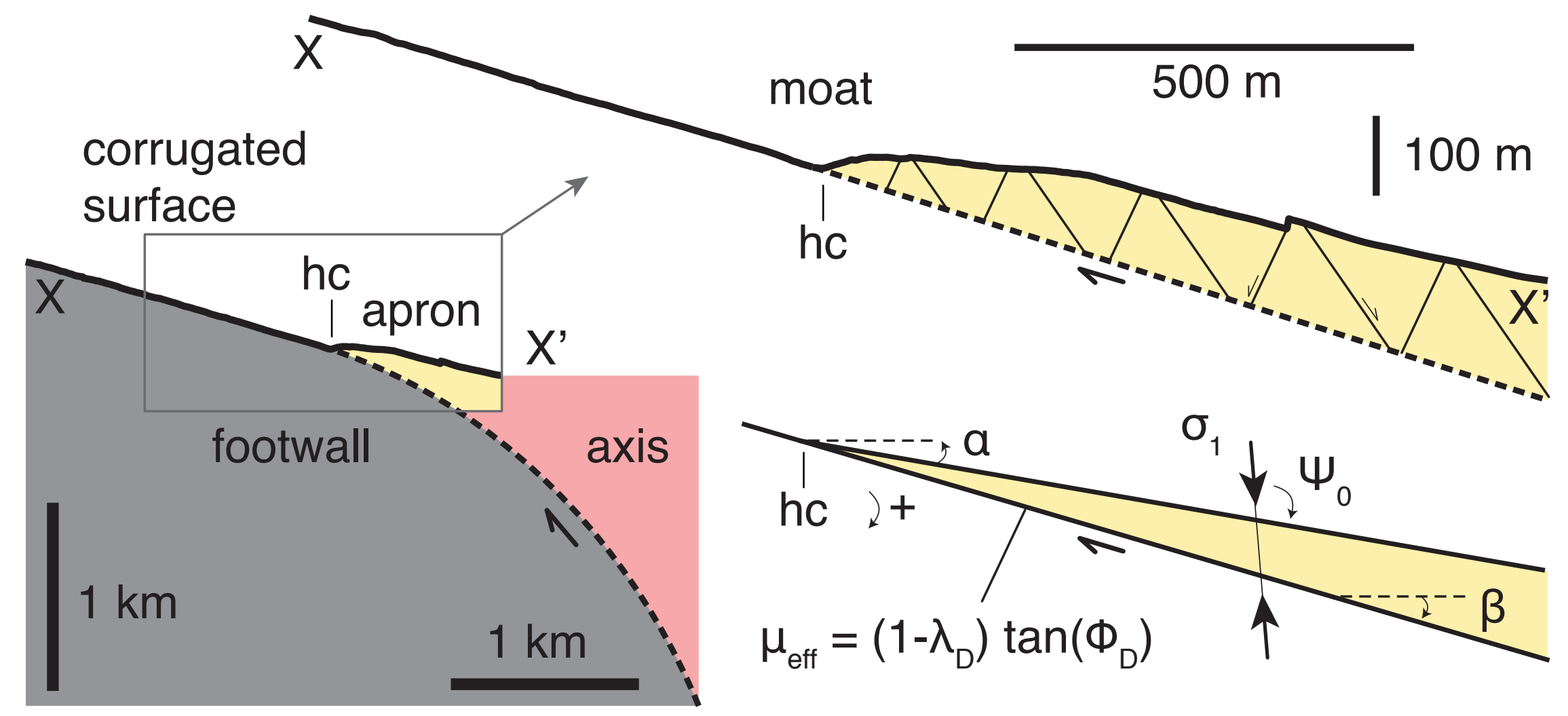

B

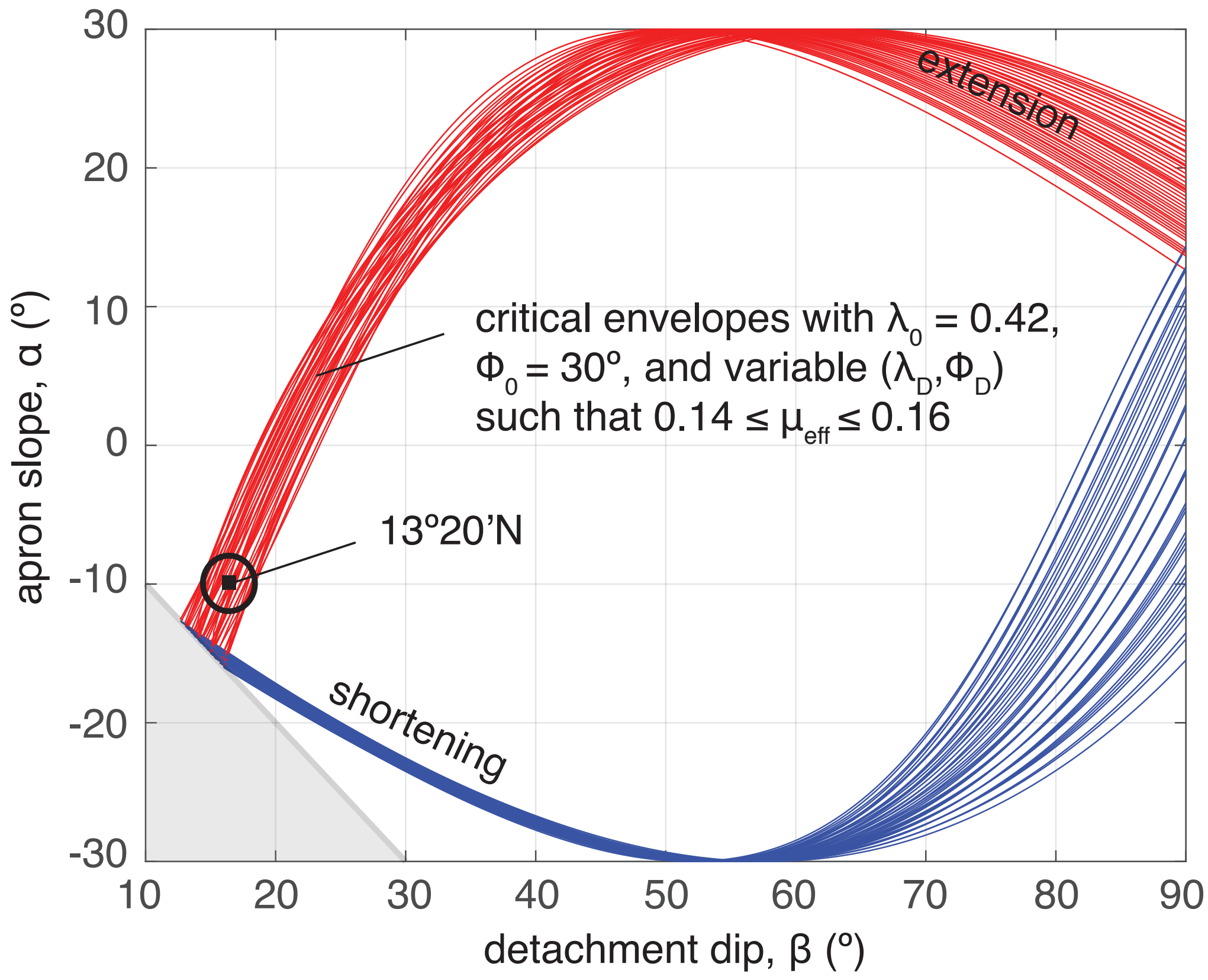


Figure 4

Click hejg to download Figure: Figure_4_slopes2friction.pdf

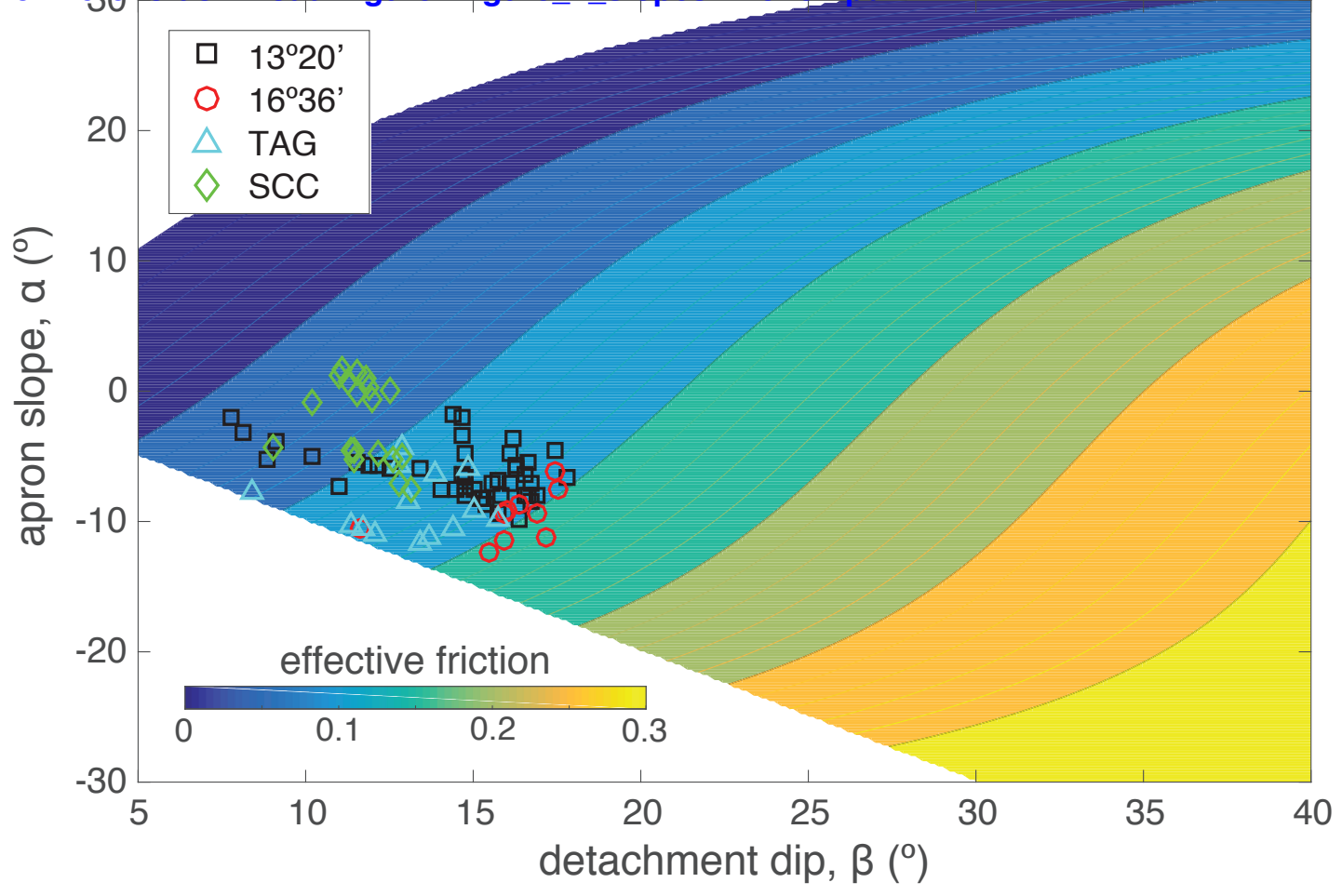


Figgre 5
Click here to download Figure: Figure_5_synthetic_cartoon.podf

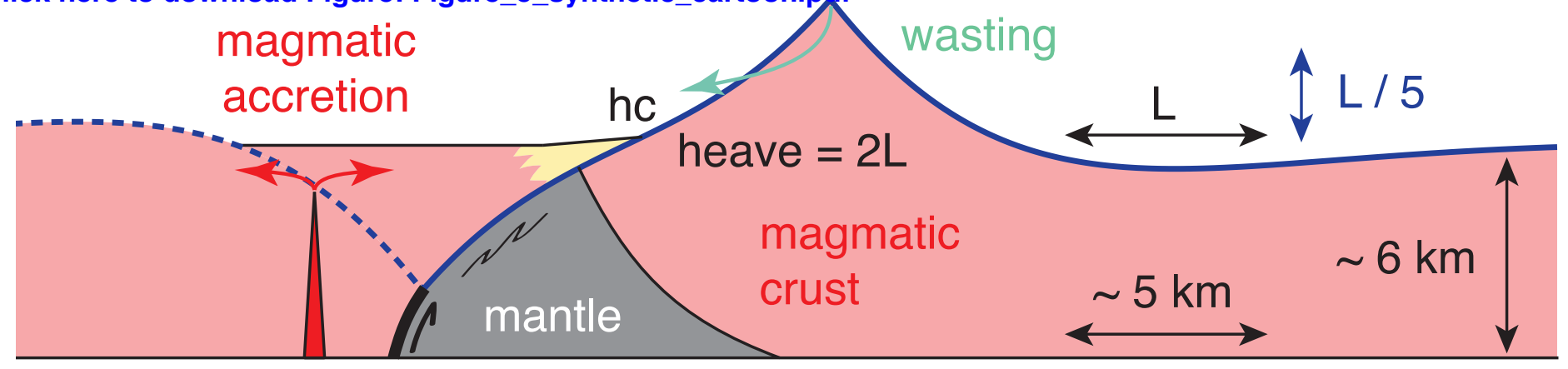

B

B fc covered footwall he

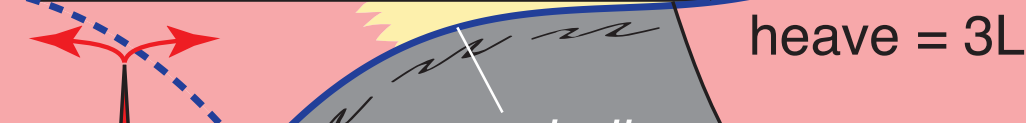

shallow slope

C

late-stage chaotic

volcanic terrain apron

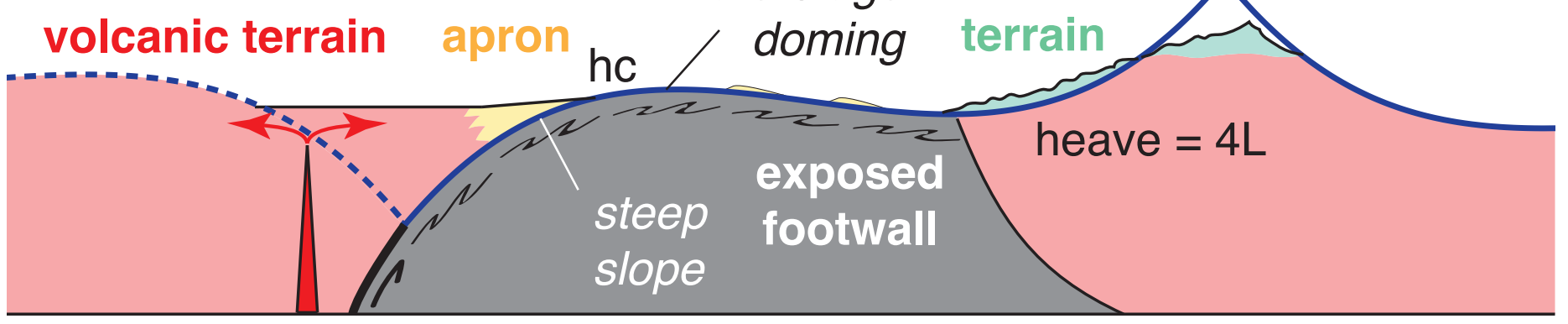

